\title{
An electrophysiological study of Duchenne dystrophy
}

\author{
A. J. McCOMAS ${ }^{1}$, R. E. P. SICA ${ }^{2}$, AND S. CURRIE \\ From the Regional Neurological Centre, Newcastle General Hospital, \\ Newcastle upon Tyne
}

SUMMARY An electrophysiological study has been made of extensor digitorum brevis muscles in 19 boys with Duchenne dystrophy. The isometric twitches of the dystrophic muscles developed less tension and were usually slower than those in controls. Impulse conduction velocity appeared to be reduced in distal regions of nerve axons but was normal proximally. The most interesting finding was a reduction in the number of functioning units in all but one of the patients. The sizes of the surviving units suggested that the results could be explained more easily in terms of a neurogenic process than a primary myopathic one.

We wish to present the results of a comprehensive electrophysiological investigation of nerve and muscle in Duchenne dystrophy, the purpose of which has been to quantify some of the functional derangements in dystrophic muscle. One aspect of this study has been the application of a new method for estimating the number of motor units in a muscle and the attempted correlation of this result with the isometric twitch tension of the same muscle. In an earlier electrophysiological survey of this kind, made in dystrophia myotonica, certain unsuspected features of dystrophic muscle were revealed (McComas, Campbell, and Sica, 1971). Of particular interest was the demonstration of a progressive reduction in the number of functioning motor units. In the present study it will be shown that there is a loss of motor units in Duchenne dystrophy also and that most patients display two further physiological abnormalities-a marked slowing of the twitch and an apparent delay in impulse conduction along terminal stretches of motor nerve fibres. A preliminary account of some of these findings has already been given (McComas, Sica, and Currie, 1970).

\section{METHODS}

PATIENTS Nineteeen boys were studied; their ages ranged from 2 to 16 (mean $11 \cdot 3$ ) years. In these children a diagnosis of Duchenne dystrophy had previously been made on the basis of the history and physical examination combined with one or more of the following criteria-family history, muscle biopsy, serum creatine

'M.R.C. External Scientific Staff.

'British Council Scholar: present address: Hospita Ramos Mejia, Buenos Aires. kinase, and concentric needle electromyography (Fig. 1). The findings of the present study supported the diagnosis in that none of the children exhibited the giant muscle action potentials characteristic of 'classical' partial denervation-for example, Kugelberg-Welander syndrome; see McComas and Sica (1971).

CONTROLS Nineteen boys served as control subjects; they were healthy volunteers with no history of neurological disease and their ages ranged from 3 to 16 years (mean 10.4).

ELECTROPHYSIOLOGICAL TECHNIQUES The following investigations were performed, using methods described previously (McComas, Fawcett, Campbell, and Sica, 1971a; McComas, Campbell, and Sica, 1971; Sica and McComas, 1971).

1. Estimation of the number of motor units in the extensor digitorum brevis muscle (EDB).

2. Amplitude of motor unit potentials in EDB.

For these two investigations the silver strip surface recording electrodes were 4 to $6 \mathrm{~cm}$ long and therefore rather shorter than those used in adults. To reduce stimulus artefact the indifferent electrode was placed on the medial aspect of the foot, rather than on the sole.

3. Isometric twitch tension, contraction, and halfrelaxation times of the extensor hallucis brevis muscle (EHB) - that is, the most medial subdivision of the EDB muscle belly.

4. Conduction velocity in motor fibres of deep peroneal nerves together with measurement of 'terminal latency' - that is, from ankle to EDB.

Tetanic stimulation of nerves, for the investigation of neuromuscular transmission, was not performed.

STATISTICAL TREATMENT Means have been expressed with standard deviations throughout the text. The significance of a difference between two means was calculated using Student's $t$ test. 


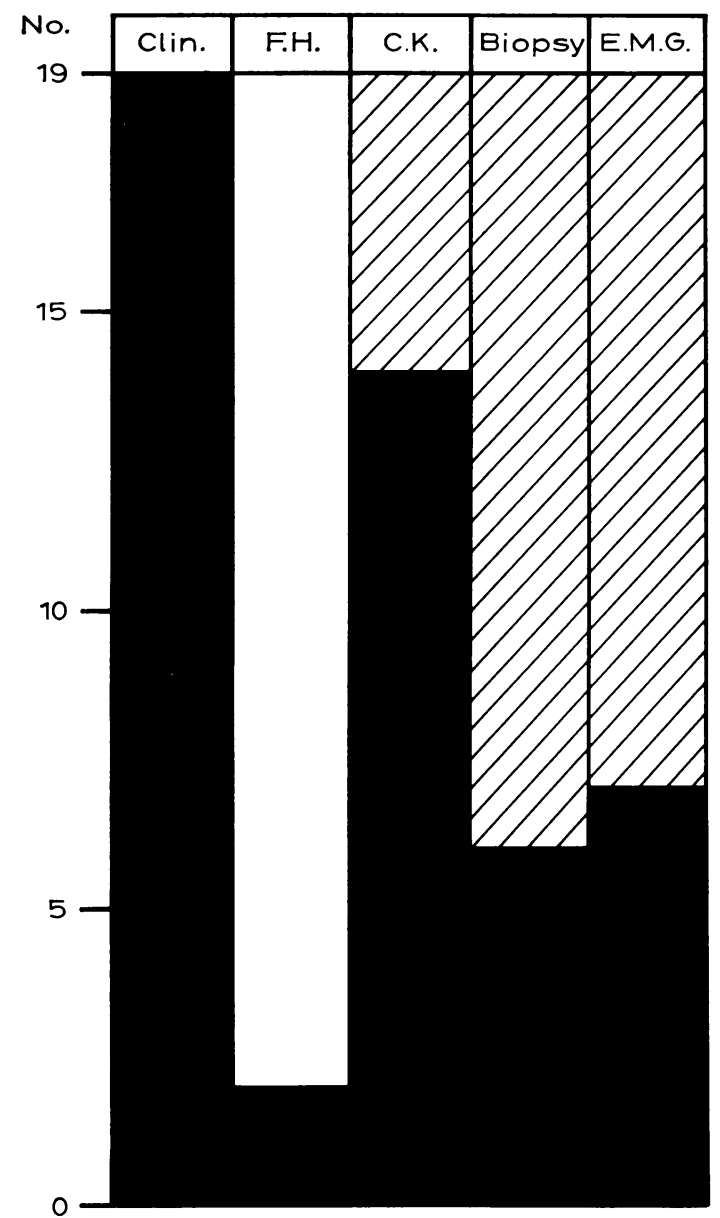

FIG. 1. Criteria used for diagnosis of Duchenne dystrophy in the 19 patients of the present study. Clin., clinical findings (history and physical examination); F.H., family history; C.K., serum creatinine kinase. $\square$ Positive. $\square$ Negative. .yl/ Not performed.

\section{RESULTS}

ISOMETRIC TWITCH OF EXTENSOR HALLUCIS BREVIS MUSCLE From Fig. 2b it would appear that, in a healthy boy, the maximum isometric twitch tension of EHB slowly increased between the ages of 3 and 13 before undergoing a marked enhancement to reach adult values. In some dystrophic children the muscles also became stronger with increasing age, while in others the functional deterioration continued. In general, the twitch tension of a dystrophic muscle was only roughly half that in a normal child of the same age. The time courses of the dystrophic twitches were also examined and it was found that in most $\bar{z}$ patients both the contraction and half-relaxation times were abnormally prolonged (Fig. 3). Thus in 11 of 16 patients the contraction times fell outside the upper limits of the normal range $(78 \mathrm{msec})$ and the largest value observed was $105 \mathrm{msec}$ (in a 12 year old boy). An example of slowed contraction and relaxation is given in Fig. 2a (lower), which shows the largest isometric twitch recorded in a dystrophic patient. From the present results it appeared that the slowing of the contraction phase $\stackrel{\vec{S}}{\rightarrow}$ was not related to the weakness of the muscle; 0 on the other hand, there was a tendency for the $\underline{\underline{C}}$ slowing to be more pronounced in older patients (correlation coefficient with age $=0.51$ ). This last observation was of interest, for it has already been shown that in healthy subjects the contraction times reach adult values by the age of 3 years (Sica and $P$ McComas, 1971). Similarly, out of 13 boys in $\overrightarrow{\vec{\omega}}$ whom the half-relaxation time could be measured $\mathscr{\omega}$ accurately, abnormal values were found in eight. The mean values for dystrophic contraction and $\frac{7}{0}$ half-relaxation times $(84 \pm 10.0$ and $88 \pm 17.9 \mathrm{msec}) \underset{\perp}{\omega}$ were significantly different from corresponding values in controls $(67 \pm 6.1$ and $64 \pm 9.7$ msec respectively; $\mathrm{P}=<.001$ for both parameters).

ESTIMATED NUMBERS OF MOTOR UNITS IN EDB Figure $\frac{8}{8}$ shows the incremental responses recorded from dystrophic EDB muscle as the stimuli to the deep peroneal nerve were gradually increased above the threshold level. On the assumption that each incre $\overrightarrow{0}$ ment represented the recruitment of an additionat motor unit, it was possible to calculate the average size of a motor unit potential; by dividing this average value into the maximum evoked muscle response, an approximate estimate of the number of motor units in EDB could be obtained (see also McComas et al., 1971a). In the example depicted in Fig. 4a the average size of the motor unit potentials was $40 \mu \mathrm{V}$ (mean of eight potentials) and the maximum muscle response was $2.08 \mathrm{mV}$, corresponding to an estimated 52 units. For comparison, the lowest value observed in 16 control subjects was 121 units and the mean number was $186 \pm 43$ units. In a larger series of healthy subjects in which the controls of the present study were combined with an additional 31 males and females below the age of 60 , the lowest estimate was also 121 motor units and the mean was $195 \pm 59$. Of the dystrophic children, however, only one had a normal number of motor units and the mean value of $53 \pm 37.9$ units differed significantly from the control mean $(P=<0.001)$. Unlike the $\mathrm{N}$ situation in dystrophia myotonica (McComas et al., o 1971b), there was no correlation between the number $N$ of surviving units and the age of the child with $N$ 


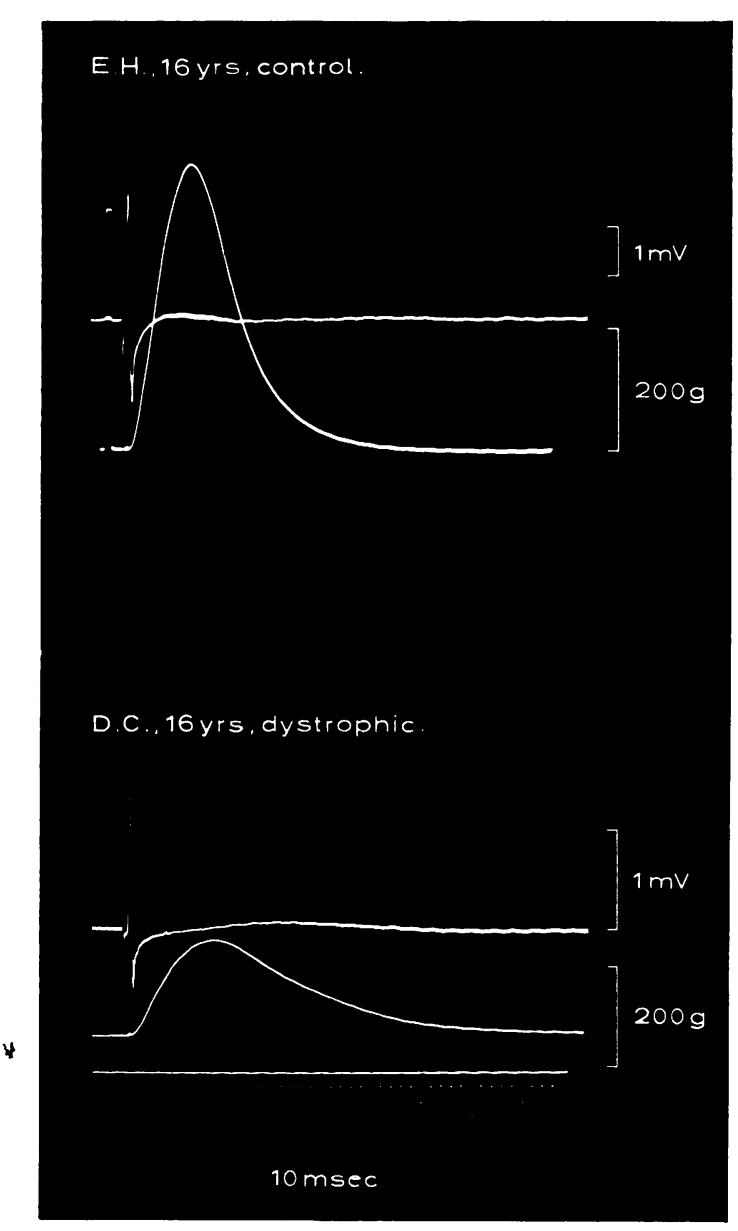

FIG. 2a. Isometric EHB twitches and evoked muscle action potentials in two 16 year old boys, of whom one was normal (upper) and the other dystrophic (lower); contraction times 65 and 84 msec respectively.

Duchenne dystrophy. Thus the only child with a normal number of units (163) was a 15 year old boy, while the two youngest patients, aged 2 and 3, were judged to have 42 and 27 units respectively.

SIZES OF DYSTROPHIC MOTOR UNITS The sizes of the surviving motor units in dystrophy were estimated on the basis of the EHB twitch tensions and on the amplitudes of the motor unit potentials in the incremental evoked responses. So far as the amplitudes of the motor unit potentials were concerned, a total of 212 potentials was measured from 18 dystrophic muscles. Although the mean amplitude of these, $19.8 \pm 14.1 \mu \mathrm{V}$, was significantly smaller

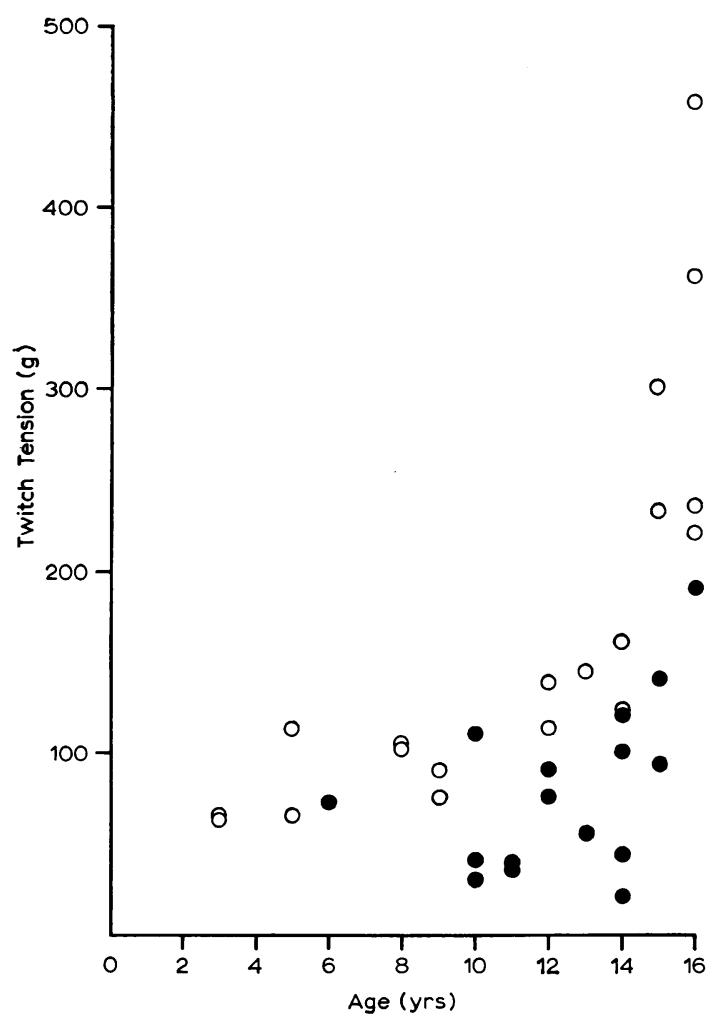

FIG. 2b. Isometric EHB twitch tensions as a function of age in patients $(\mathrm{O})$ and controls $(\mathrm{O})$.

than the control mean, $27 \cdot 0 \pm 25.0 \mu \mathrm{V}$, it can be seen from Fig. $4 \mathrm{~b}$ that the majority of amplitudes in dystrophy fell within the normal range. Furthermore, the distribution of the dystrophic values, with a clearly defined mode of 12 to $16 \mu \mathrm{V}$, suggested that few potentials were likely to have been undetected because they were smaller than the noise level $(4 \mu \mathrm{V})$ of the recording system.

The estimation of motor unit sizes on the basis of the isometric twitch tensions was complicated by the effect of the patient's age. In Fig. 5 the two dotted lines depict the theoretical tensions which would be developed by varying numbers of units in a normal child 8 to 9 years old and in one aged 15 to 16 (data from Fig. 2b). If, in dystrophic boys aged 8 to 16 , the motor units were of normal size, then the tensions should have fallen close to, or within, the area bounded by these two lines. In fact, while nine of the recorded EHB tensions came into this category there were a further six patients who had substantially larger twitches. A more exact portrayal of the 

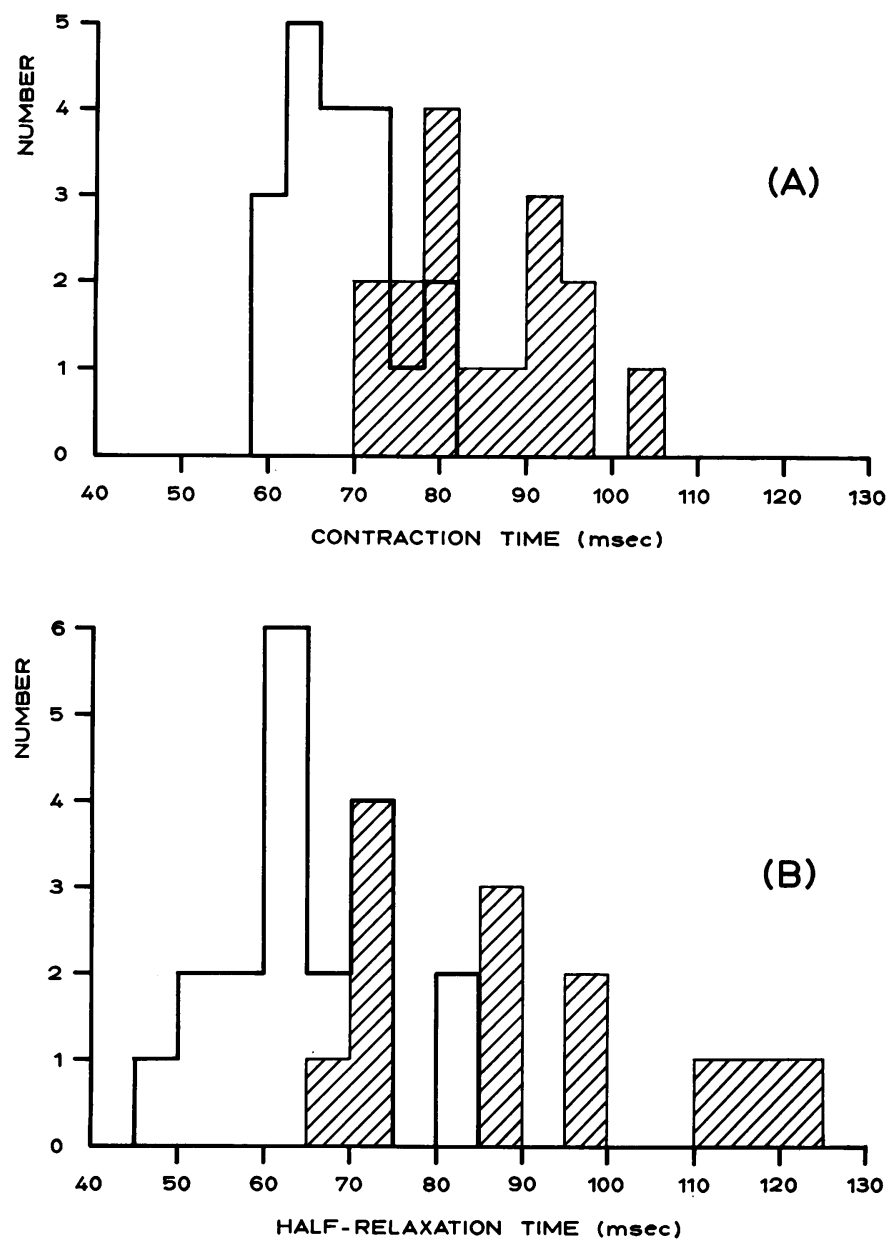

FIG. 3. (A) Contraction times of isometric EHB twitches in 19 controls (open columns) and 16 patients (hatched columns); mean values $67 \cdot 3 \pm 6 \cdot 1 \mathrm{msec}$. and $83 \cdot 9 \pm 10 \cdot 1 \mathrm{msec}$ respectively. (B) Half-relaxation times of isometric EHB twitches in 19 controls (open columns) and 14 patients (hatched columns); mean values $63.9 \pm 9.7 \mathrm{msec}$ and $88 \cdot 1 \pm 17 \cdot 9$ msec respectively. relationship between the number of units, twitch tension and age is given in the simulated three dimensional diagram of Fig. 6. In conclusion, the results of the twitch tension and potential amplitude studies both suggested that many of the surviving motor units in a dystrophic muscle were of approximately normal size.

MOTOR NERVE CONDUCTION VELOCITIES AND TERMINAL LATENCIES The conduction velocities of the fastest conducting motor nerve fibres were measured in the deep peroneal nerves of 18 patients (Fig. 7a). Only two patients, both aged 13 , had values $(37 \mathrm{~m} / \mathrm{sec})$ which were below the lower limit of the normal range for this laboratory $(40 \mathrm{~m} / \mathrm{sec})$ and there was no significant difference between the means for the normal and dystrophic populations $(52.1 \pm 5.0$ and $51 \cdot 1 \pm 6.9 \mathrm{~m} / \mathrm{sec}$ respectively; $P=>0.5)$. Measure- ments were also made of the terminal latency- $\overrightarrow{\vec{P}}$ that is, the time elapsing between stimulation of the deep peroneal nerve at the ankle and the onset of evoked activity in the end-plate zone of EDB (Fig. 7b). In control subjects the terminal latency increased by about 2 msec between the ages of 4 and 16 , presumably on account of the greater length of nerve separating the points of stimulation and recording. In dystrophic children the latencies were usually greater at each age, the largest value observed being $6.7 \mathrm{msec}$. The difference between the normal mean $(3.5 \pm 0.7 \mathrm{msec})$ and the patient mean $(4.4 \pm$ $1.1 \mathrm{msec})$ was significant $(\mathrm{P}=<0.01)$.

\section{DISCUSSION}

Although the Duchenne type of muscular dystrophy is considered to affect proximal muscles most 


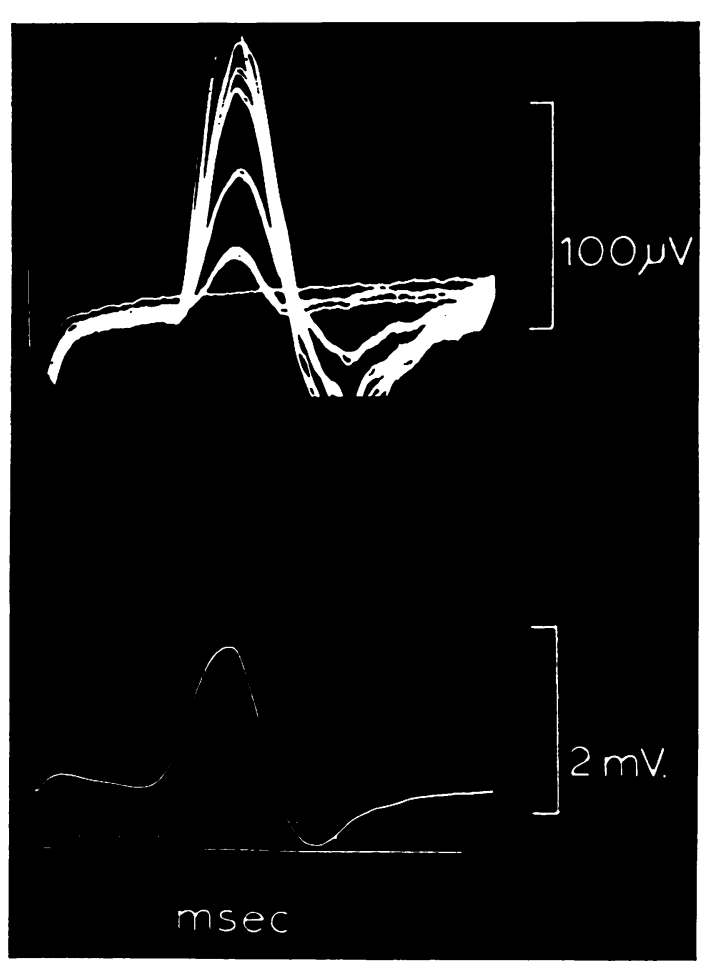

FIG. 4a. Evoked muscle action potentials in EDB after juxtathreshold and supramaximal stimulation of deep peroneal nerve (upper and lower traces respectively). In the upper record only the five incremental responses with the lowest thresholds are shown.

severely, the present study has shown that tension development in the extensor hallucis brevis, a distal muscle, is also greatly impaired. Yet, in spite of pathological involvement, some of the EHB muscles still appear to undergo a modest improvement in strength as the patients grow older, thereby mimicking the marked muscle development which occurs in a normal boy at puberty (McComas, Sica, and Upton, unpublished observations). The other abnormal feature of the dystrophic twitch noted in the present study was the slowing of contraction and relaxation. This last observation confirmed previous findings in the adductor pollicis muscle (Desmedt, Emeryk, Renoirte, and Hainaut, 1968; Roe, Yamaji, and Sandow, 1967; see also Botelho, Beckett, and Bendler, 1960), the first dorsal interosseus muscle of the hand (McComas and Thomas, 1968), and the brachial biceps muscle (Buchthal and Schmalbruch, 1970) of patients with Duchenne dystrophy. As in these other investigations, the slowing found in the

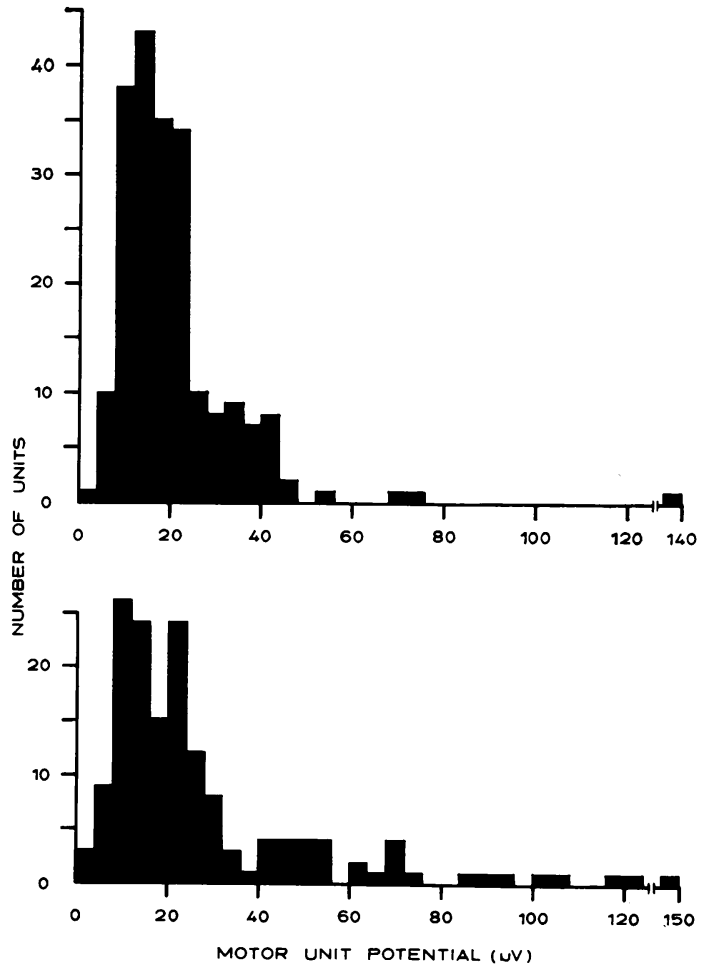

FIG. 4b. Amplitudes of motor unit potentials-that is, evoked response increments-in patients (mean 19.8 $\pm 14 \cdot 1$ $\mu V, n=212$; upper histogram) and controls (mean $27 \cdot 0 \pm 25 \cdot 0 \mu \mathrm{V}, n=157$; lower histogram). Means differ significantly $(P=<0.001)$.

present study could not be accounted for by repetitive firing of muscle action potentials or by differences in muscle temperature. Although it was possible that the presence of fibrosis within the muscle belly may have damped the twitch to some extent, it seemed unlikely that this was the only explanation of the slowing. Thus McComas and Thomas (1968) observed very marked slowing in the youngest patient of their series, in whom the least pathological changes would have been anticipated. From the work of Buchthal and Schmalbruch (1969), in which twitch measurements and a muscle biopsy were performed on the same muscle, it would appear that the slowing is largely due to a high proportion of type I muscle fibres among the surviving population. The measurement of impulse conduction in motor nerve fibres was felt to be important in view of the conflicting findings reported previously. Thus, in patients with Duchenne dystrophy, Henriksen (1956) found conduction velocities within the normal range, while 


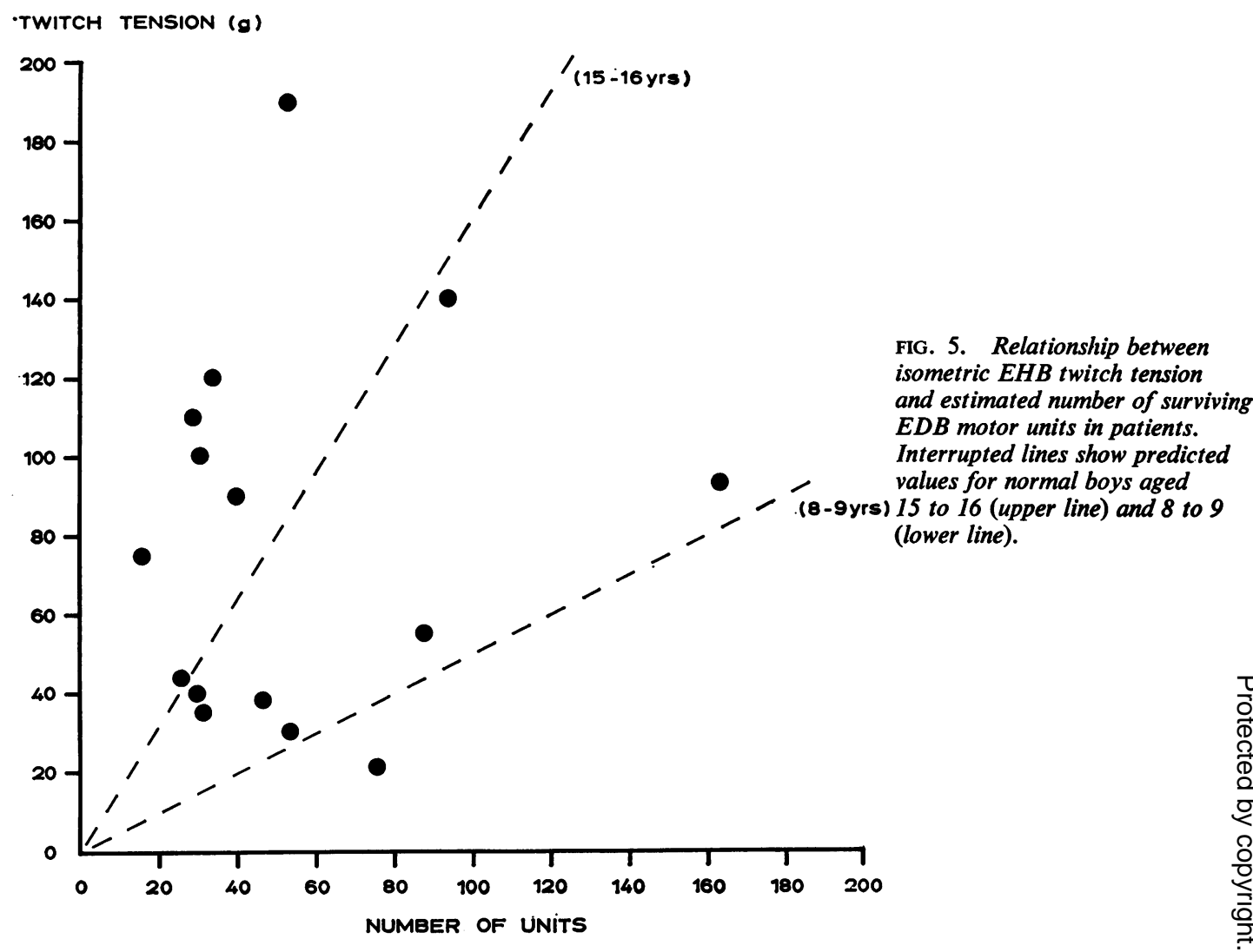

Nakao, Kito, Muro, Tomonaga, and Mozai (1968) found slowing in $21 \%$ of 112 dystrophic patients, most of whom were of the Duchenne type. In another extensive study of Duchenne dystrophy, Jayam, Raju, Paddya, and Desai (1970) found a significant reduction of impulse conduction velocities in median and ulnar nerves but not in deep peroneal nerves. In the present study, a slight reduction in conduction velocity was noted in only two of 18 patients. In contrast with this finding, the terminal latencies in the dystrophic boys were commonly increased. Since the evoked muscle responses were recorded at the end plate zone, the increased terminal latency could have resulted only from slowed impulse conduction in terminal nerve branches or from delayed neuromuscular transmission, or from both these factors. Although there is insufficient data for statistical evaluation, inspection of Fig. 7b suggested that two of the three youngest patients may have had prolonged latencies. In older children the slowing had less significance, since the possibility of nerve trauma could not be excluded; many of these boys were grossly disabled, commonly with inversion deformities at the ankles, and some wore calipers.

As in the study of dystrophia myotonica (McComas et al., 1971b), the most interesting finding was the reduction in the number of motor units in dystrophic muscles. Unlike dystrophia myotonica, however, there was a marked variation in the number of surviving units among patients of similar ages. This variation was apparently sufficient to mask any progressive reduction in the number of units with advancing age. It is not a purpose of this paper to review all the evidence for 'denervation' in various types of muscular dystrophy; instead we will simply cite five observations which have been made in the Duchenne type. These are:

1. A marked loss of motoneurones in some spinal cords (B. E. Tomlinson, personal communication).

2. The presence of grouped atrophy in dystrophic muscles (Jędrzejowska-Kułakowska, HausmanowaPetrusewicz, Gawlik, Rafałowska, and Słucka, 1968).

3. The presence of abnormal end plates, sometimes 


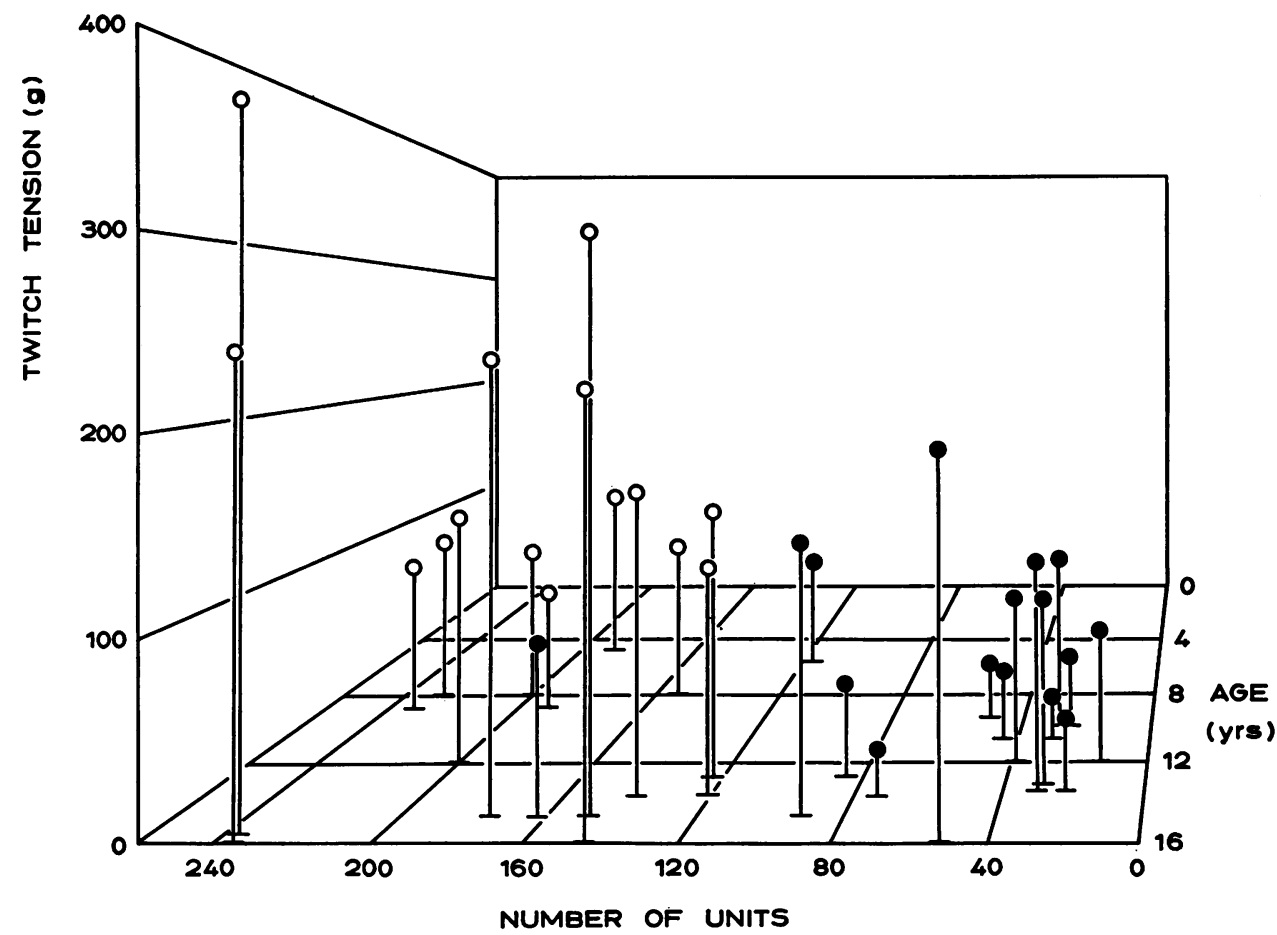

FIG. 6. Relationship between isometric EHB twitch tension, estimated number of surviving EDB motor units, and age, in patients $(\Theta)$ and controls $(O)$.

(A)

(B)
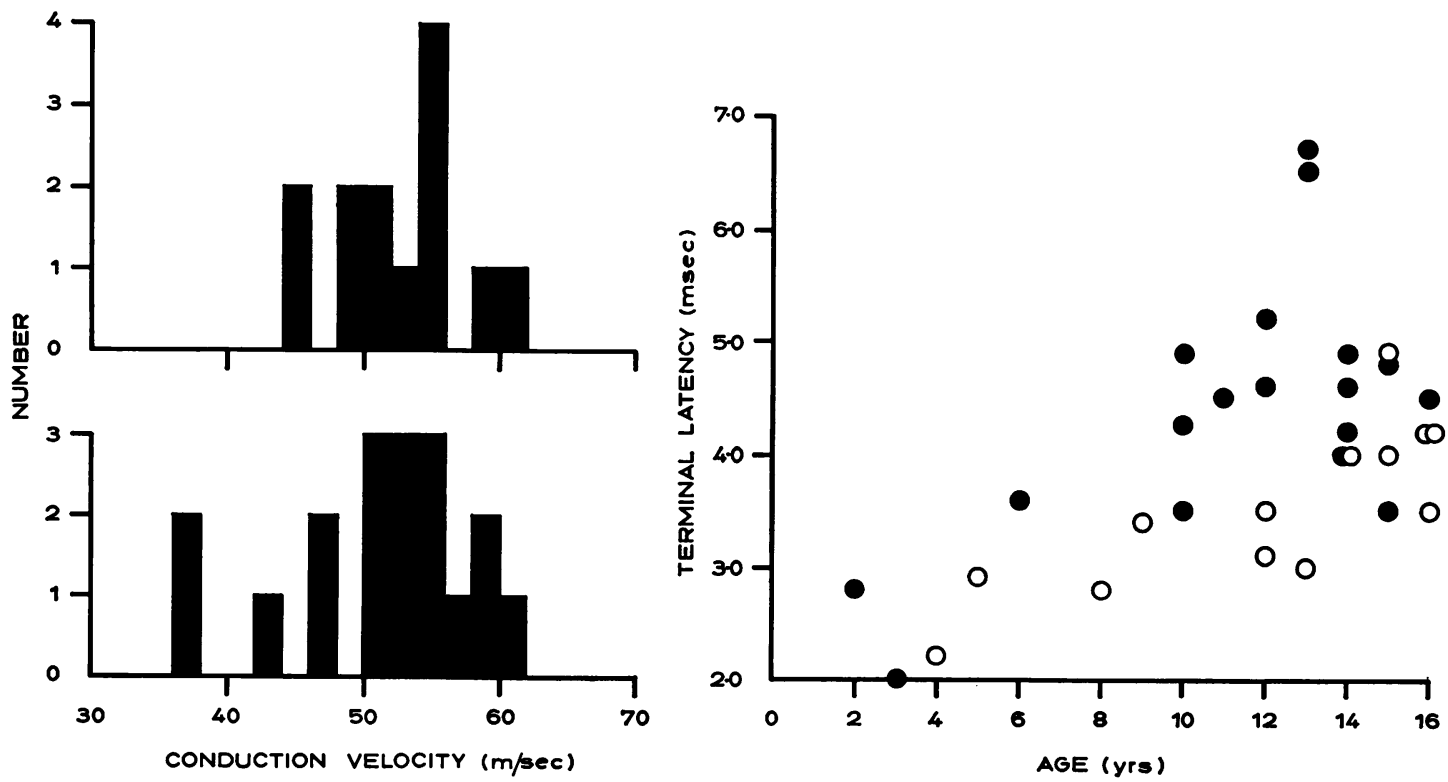

FIG. 7. (A) Conduction velocity of deep peroneal motor nerve fibres in 13 controls and 18 patients; means $52 \cdot 1 \pm 5 \cdot 0$ and $51 \cdot 1 \pm 6.9 \mathrm{~m} / \mathrm{sec}$ respectively. (B) Latency of $E D B$ response after stimulation of deep peroneal nerve at ankle in controls $(O)$ and patients $(O)$ as a function of age. 
on minimally affected muscle fibres (Jedrzejowska, 1968).

4. The detection of fibrillation potentials during electromyographic examination of dystrophic muscles (Norris and Chatfield, 1955).

5 . The presence of lymphocytes sensitized to antigens of peripheral and central nervous origin in the blood of dystrophic patients (Caspary, Currie, and Field, 1971).

The possibility that the motor nerve changes were secondary to the loss of muscle fibres during a primary myopathic process must be considered. However, in dystrophia myotonica it was argued (McComas et al., 1971b) that the relatively normal sizes of the remaining motor units were not compatible with a primary myopathy. A similar conclusion could be reached for Duchenne dystrophy from the measurements of twitch tension and motor unit potential amplitude made in this study. Finally, although the possibility of trauma to nerves could not be rejected in older patients, it was clear from the present investigation that this was a relatively minor factor. The crucial observation was that severe denervation was already present in the two youngest boys, aged 2 and 3, both of whom were able to walk quite well. This last observation strongly suggested that the motor 'denervation' was a primary phenomenon and the proposition that muscular dystrophy has a neurogenic basis will be considered more fully in a subsequent paper (see also McComas et al., 1970c).

Financial support was received from the Medical Research Council, the British Council, the Muscular Dystrophy Group of Great Britain, and the Muscular Dystrophy Associations of America, Inc. Technical service was kindly provided by Mr. T. Blogg and Mr. C. Wallace and secretarial assistance by Mrs. Y. Chisholm.

\section{REFERENCES}

Botelho, S. Y., Beckett, M. S., and Bendler. E. (1960). Mechanical and electrical responses of intact thenar muscles to indirect stimuli. Study of patients with pseudohypertrophic muscular dystrophy. Neurology (Minneap.), 10, 601-612.

Buchthal, F., and Schmalbruch, H. (1970). Contraction times and fibre types in normal and diseased human muscle. $Z$ In Muscle Diseases, pp. 131-137. Edited by J. N. Walton, 믄 N. Canal, and G. Scarlato. Excerpta Medica: Amsterdam. Caspary, E. A., Currie, S., and Field, E. J. (1971). Sensitized lymphocytes in muscular dystrophy: evidence for a neural factor in pathogenesis. J. Neurol. Neurosurg. Psychiat, 34, 353-356.

Desmedt, J. E., Emeryk, B., Renoirte, P., and Hainaut, K. (1968). Disorder of muscle contraction processes in sexlinked (Duchenne) muscular dystrophy, with correlative electromyographic study of myopathic involvement in small hand muscles. Amer. J. Med., 45, 853-872.

Henriksen, J. D. (1956). Conduction Velocity of Motor Nerves in Normal Subjects and Patients with Neuromuscular Disorders. M.S. (Phys. Med.) Thesis. University of Minnesota.

Jayam, A. V., Raju, T. N. K., Pandya, S. S., and Desai A. D. (1970). Motor nerve conduction in Duchenne type of muscular dystrophy. Neurology (India), 18, 8-12.

Jędrzejowska, Hanna (1968). Badania histopatologiczne ڤొ wewnątrzmiesśniowych ruchowych włokien nerwowych w postępującej dystrofii mięśniowej. Neuropath. pol., 6, . 359-402.

Jędrzejowska-Kułakowska, Hanna, Hausmanowa-Petruse- $\vec{\omega}$ wicz, Irena, Gawlik, Zbigninew, Rafałowska, Janina, and Słucka, Cecylıa (1968). Zweryfikowany sekcyjnie przypadek postępującej dystrofii mięśniowej typu Duchenne' A. Neuropath. pol., 6, 71-85.

McComas, A. J., Fawcett, P. R. W., Campbell, M. J., and Sica, R. E. P. (1971a). Electrophysiological estimation of the number of motor units within a human muscle o J. Neurol. Neurosurg. Psychiat., 34, 121-131.

McComas, A. J., Campbell, M. J., and Sica, R. E. P. (1971b尔 Electrophysiological study of dystrophia myotonica. Neurol. Neurosurg. Psychiat., 34, 132-139.

McComas, A. J., and Sica, R. E. P. (1971). Properties of motor units in normal and partly denervated muscle $O$ J. Physiol. (Lond.) (In press).

McComas, A. J., Sica, R. E. P., and Currie, S. (1970c) Muscular dystrophy: evidence for a neural factor. Nature (Lond.), 226, 1263-1264.

McComas, A. J., and Thomas, H. C. (1968). A study of the muscle twitch in the Duchenne type muscular dystrophy. J. neurol. Sci., 7, 309-312.

Nakao, K., Kito, S., Muro, T., Tomonaga, M. and Mozai, T. (1968). Nervous system involvement in progressive muscular dystrophy. Proc. aust. Ass. Neurol., 5, 557-564.

Norris, F. H., and Chatfield, P. O. (1955). Some electrophysiological aspects of muscular dystrophy. Electroenceph. clin. Neurophysiol., 7, 391-397.

Roe, R. D., Yamaji, K. Y., and Sandow, A. (1967). Contractile responses of dystrophic muscles of mouse and man. pp.299-304. In Exploratorv Concepts in Muscular Dystrophy and Related Disorders. Edited by A. T. Milhorat. Excerpta Medica: Amsterdam.

Sica, R. E. P., and McComas, A. J. (1971). Fast and slow twitch units in a human muscle. J. Neurol. Neurosurg. Psychiat., 34, 113-120. 